establishing the diagnosis of hyaline membrane disease.

This conclusion differs from findings that we have published based on 295 infants, ${ }^{1}$ in which the lecithin:sphingomyelin ratio measured on pharyngeal secretions obtained within six hours of birth identified babies with hyaline membrane disease (figure). ${ }^{23}$

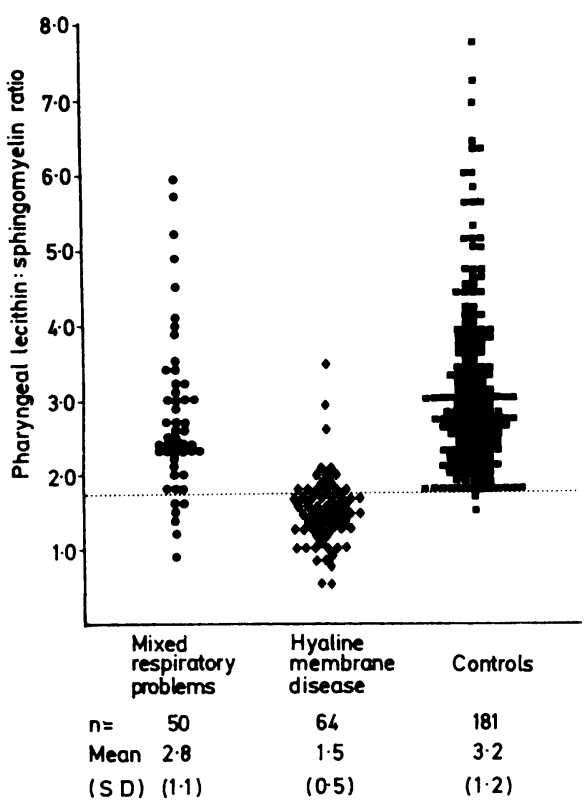

Comparisons of pharyngeal lecithin :sphingomyelin ratio in babies with mixed respiratory problems (transient tachypnoea and pneumonia), hyaline membrane disease, and controls. There is a significant difference in the proportion of immature lecithin:sphingomyelin ratios $(<1.8)$ between infants with hyaline membrane disease and those with mixed respiratory disorders (48/64:6/50, $\chi^{2}=44.6, \mathrm{p}<0.0001$ ).

There was a highly significant difference in the proportion of immature lecithin :sphingomyelin ratios $(<1.8)$ between infants with hyaline membrane disease and those with other respiratory disorders (predominantly transient tachypnoea and pneumonia) $(\mathrm{p}<0.0001)$. A lecithin :sphingomyelin ratio of $<1.8$ detected $75 \%$ (48 out of 64 ) of cases of hyaline membrane disease with a false positive rate of $3 \%$ (eight out of 231). Thus the sensitivity of the test is $75 \%$ and the specificity is $97 \%(223 / 231){ }^{4}$

It is not always possible to assign a respiratory diagnosis with certainty to a newborn infant managed on intermittent positive pressure ventilation from birth since this treatment frequently obscures both clinical and radiological diagnostic features. In such infants a measurement of pulmonary surfactant is of particular value in supporting the clinical diagnosis. It is unacceptable, in our view, however, to include such babies in any study aiming at evaluating the diagnostic reliability of a test of surfactant status. It is not clear how many babies in Dr James's series labelled as having hyaline membrane disease or congenital pneumonia were in fact ventilated from birth. None of the 64 infants independently identified as having hyaline membrane disease in our series were on intermittent positive pressure ventilation from birth onwards.

The lecithin:sphingomyelin ratio is ideally suited for confirming the comparability of infants randomly allocated to trials of surfactant therapy, ${ }^{5}$ high frequency ventilation (unpublished results), and other treatments. We cannot agree with the conclusion of Dr James and colleagues that pulmonary surfactant deficiency is unreliable in establishing the diagnosis of hyaline membrane disease.

P A JENKINS W TARNOW-MORDI J D BAUM Department of Paediatrics,
John Radcliffe Hospital,

' Jenkins PA, Baum JD. Respiratory distress syndrome. In: Wald NJ, ed. Antenatal and neonatal screening. Oxford: Oxford University Press, 1984:298-313.

Gluck L, Kulovich MV, Borer RC, Brenner PH,
Anderson CG, Spellacy WN. Diagnosis of the Anderson CG, Spellacy WN. Diagnosis of the

3 Barr PA, Jenkins PA, Baum JD. Lecithin/sphingomyelin ratio in hypopharyngeal aspirate of newborn infants. Arch Dis Child 1975;50:856-61.

Anonymous. Glossary of terms. In: Wald NJ, ed. Antenatal and neonatal screening. Oxford: Oxford Antenatal and neonatal scree
University Press, 1984:552-4

s Wilkinson AR, Jeffrey JA, Jenkins PA. Controlled trials of dry surfactant in preterm infants. Arch
Dis Child 1982;57:802.

\section{Treatment of myopia}

SIR,-I want to try to correct some of the exaggeration of $\mathrm{Mr}$ Thomas Stuart-Black Kelly's letter (2 June, p 1692). Firstly, myopia is not a disease and cannot be regarded as anything more than an error of refraction except in its higher degrees, when there may indeed be retinal and other complications. It is the fundus changes rather than the degree of myopia that is the disease, and although only likely with errors in excess of 7 dioptres (a small minority of myopes) such changes can be absent in higher myopes and can occur in low myopes or rarely hypermetropes.

Secondly, myopia is a useful condition, especially for ophthalmic surgeons or others doing fine, close work. Myopes come into their own in middle age when others need reading glasses.

Finally, the rationale of $\mathrm{Mr}$ Kelly's alternative medicine is that bifocals will abolish the need for the growing child to accommodate - that is, to hinder a most useful function of the eye which has not been proved to be a cause of high myopia. All I would advise is that the growing child wears the normal correction for his myopia so that he sees the blackboard clearly and does not screw up his eyes. Also, so that he does not bury his nose in his book, he should wear the glasses even for reading, thereby building up the normal relation between convergence and accommodation. Otherwise exophoria or divergent strabismus may ensue.

John Primrose

Ilford,
Essex

Mesothelioma due to domestic exposure to asbestos

SIR,-The unreviewed report by Dr G C Ferguson and Dr H Watson (2 June, p 1654) of two sisters who both developed pleural mesotheliomas is of considerable interest. Several occurrences of two or more cases of mesothelioma within the nuclear family have been reported, and this is probably not simply due to a shared source of asbestos exposure. ${ }^{1}$
Before either the diagnosis or aetiology can be accepted, however, further information is required. Was the diagnosis confirmed in both cases by a pathologist with particular experience in mesothelioma histology ? In a recent review of cases diagnosed as mesothelioma by local pathologists in the USA, only $26 \%$ could be accepted as definite, probable, or even possible by a member of the mesothelioma reference panel. ${ }^{2}$ The importance of accurate diagnosis is underlined by the prolonged survival of one of the sisters after pleurectomy, as surgery has rarely been found to influence survival of patients with diffuse mesothelioma.

Dr Ferguson and Dr Watson suggest that the mesotheliomas arose from wire brushing of a white asbestos cement roof. This is to ignore the strong epidemiological evidence now accumulating that chrysotile, as distinct from amphibole asbestos, plays little or no part in mesothelioma aetiology. Acheson and Gardner in their 1983 report to the UK Health and Safety executive stated: "Subsequent evidence has supported our previous view that peritoneal mesothelioma for practical purposes never, and pleural mesothelioma rarely, has occurred in man in relation to exposure to chrysotile alone." 3 Was a microscopic study of the lung fibre burden carried out in the fatal case?

In 1976 Milne reported the cases of two sisters living in Australia who died of mesothelioma in which most careful questioning failed to find any exposure to asbestos. ${ }^{4}$ For most of us nowadays some casual contact with asbestos is inevitable. But post hoc does not always mean propter hoc, and not all cases of mesothelioma are due to exposure to asbestos.

Kevin Browne

Cape Industries Ltd

London WIY $4 A B$

TBA Industrial Products Ltd,

Rochdale, Lancs OL12 7EQ

'Browne K. Asbestos-related mesothelioma: epidemiological evidence for asbestos as a promoter. Arch Environ Health $1983 ; 38: 261-6$.

2 Wright WE, Sherwin RP, Dickson EA, Bernstein L, Fromm JB, Henderson BE. Malignant mesothelioma ncidence, asbestos exposure, and reclassification of histopathology. Br f Ind Med 1984;41:39-45.

3 Acheson ED, Gardner MJ. Asbestos: the control limit for asbestos. London: $\mathrm{HMSO}, 1983$.

- Milne JEH. Thirty two cases of mesothelioma in Victoria, Australia: a retrospective survey related to occupational asbestos exposure. $\mathrm{Br} \mathcal{F}$ Ind $\mathrm{Med}$
$1976 ; 33: 115-22$.

${ }_{*}^{*}$ *Dr Ferguson and Dr Watson reply below. -ED, $B M \mathcal{F}$.

SiR,-Lack of space prevented us from stating that the relation between asbestos exposure and the development of mesothelioma in these two sisters had not been definitely established, particularly because a study of the lung fibre burden was not carried out in the fatal case.

In both of our cases the diagnosis of mesothelioma was made by our consultant pathologists, and reference to the failure of local American pathology services to diagnose this condition correctly may not be appropriate. We would, of course, be happy to arrange for histological slides from these cases to be submitted to any reference pathologist.

Prolonged survival with or without surgery does not rule out mesothelioma-Law et al found two patients who survived up to eight years from diagnosis. ${ }^{1}$ The basic question is whether short term heavy non-occupational exposure to asbestos is a causative factor in 